\title{
Influence of fine particulate matter and its pure particulate fractions on pulmonary immune cells and cytokines in mice
}

\author{
ZHOUGUANG JIAO, ZHANBO WEN, WENHUI YANG，LINGFEI HU and JINSONG LI
}

\author{
State Key Laboratory of Pathogen and Biosecurity, Beijing Institute of Microbiology and Epidemiology, \\ Academy of Military and Medical Sciences, Beijing 100071, P.R. China
}

Received November 18, 2019; Accepted March 22, 2021

DOI: $10.3892 /$ etm.2021.10094

\begin{abstract}
Particulate matter with a diameter $\leq 2.5 \mu \mathrm{m}\left(\mathrm{PM}_{2.5}\right)$ has a complex composition and has been associated with the incidence of cardiopulmonary disease and premature death in humans. However, whether pure particulate fractions of $\mathrm{PM}_{2.5}\left(\mathrm{PPP}_{2.5}\right)$, which are composed primarily of carbon, are responsible for the toxicity caused by ambient particulate matter (original $\mathrm{PM}_{2.5}$ particles, $\mathrm{OPP}_{2.5}$ ) is currently unclear. The present study assessed the acute toxic effects of $\mathrm{OPP}_{2.5}$ sampled in Beijing, China and of its $\mathrm{PPP}_{2.5}$ fraction in male $\mathrm{BALB} / \mathrm{c}$ mice. The mice were intratracheally instilled with a single dose of aerosolized $\mathrm{OPP}_{2.5}$ or $\mathrm{PPP}_{2.5}$. Blood, lungs and bronchoalveolar lavage fluid were collected after $24 \mathrm{~h}$ for histopathology, flow cytometry and the measurement of pro-inflammatory cytokines/chemokines and other biochemical factors. Both $\mathrm{OPP}_{2.5}$ and $\mathrm{PPP}_{2.5}$ caused acute toxicity, particularly inflammatory responses, including an increase in the levels of pro-inflammatory cytokines and an accumulation of numerous immune cells in the lungs. $\mathrm{OPP}_{2.5}$ induced a stronger inflammatory response than $\mathrm{PPP}_{2.5}$. The complex components adsorbed into the solid core granules of $\mathrm{OPP}_{2.5}$ and the granules themselves contributed to the toxic effects.
\end{abstract}

\section{Introduction}

Atmospheric particulate matter with a diameter $\leq 2.5 \mu \mathrm{m}$ $\left(\mathrm{PM}_{2.5}\right)$ has a large surface area, adsorbs toxic substances and penetrates into the lung alveoli (1-5). Epidemiological studies have demonstrated that ambient $\mathrm{PM}_{2.5}$ pollution contributes to lower respiratory tract infections, cancer of the trachea, bronchus and lungs, ischemic heart disease, cerebrovascular

Correspondence to: Dr Lingfei Hu or Professor Jinsong Li, State Key Laboratory of Pathogen and Biosecurity, Beijing Institute of Microbiology and Epidemiology, Academy of Military and Medical Sciences, 20 Dongda Street, Beijing 100071, P.R. China E-mail: huling03@163.com

E-mail:1ij-s@163.com

Key words: particulate matter, acute toxicity, histopathology, immune system, inflammation disease and chronic obstructive pulmonary disease (6-8). Therefore, ambient $\mathrm{PM}_{2.5}$ pollution increases the incidence of premature death $(6,7)$. The elderly, children and individuals with cardiopulmonary disease are particularly susceptible to the effects of $\mathrm{PM}_{2.5}$ (6-9).

Certain toxic substances, such as some heavy metals, adsorbed into $\mathrm{PM}_{2.5}$ are released into the lungs and adsorb into lung epithelial cells, resulting in penetration to blood vessels during breathing (10-14). Therefore, the respiratory and cardiovascular systems are considered to be the primary biological targets of inhaled $\mathrm{PM}_{2.5}$ (10-14). The composition of $\mathrm{PM}_{2.5}$ is complex and varies by source (2), although it is mainly comprised of soluble salts, metals, organic compounds, carbon and biological constituents (15-17). Organic and inorganic compounds adsorbed into $\mathrm{PM}_{2.5}$ have been demonstrated to be closely associated with the biologically toxic effects of the particles (18-20). While the toxic effects of the water- and fat-soluble components of $\mathrm{PM}_{2.5}$ have been investigated (21-24), little research has been conducted on pure $\mathrm{PM}_{2.5}$ particles $\left(\mathrm{PPP}_{2.5}\right)$, which are primarily comprised of carbon. Particles of carbon black have been studied $(25,26)$; however, its toxic effects vary from those of $\mathrm{PPP}_{2.5}$. It is therefore necessary to characterize the biologically toxic effects of $\mathrm{PPP}_{2.5}$.

In previous studies $(17,27)$, atmospheric $\mathrm{PM}_{2.5}$ was sampled from an urban area of Beijing, China, which tested the original $\mathrm{PM}_{2.5}$ particles $\left(\mathrm{OPP}_{2.5}\right)$ : $\mathrm{PPP}_{2.5}$ (mainly comprised of insoluble solid components), water-soluble fractions of $\mathrm{PM}_{2.5}$ and fat-soluble fractions of $\mathrm{PM}_{2.5}$. The chemical and biological constituents of these four matrices were characterized and their toxic effects on A549 human alveolar basal epithelial cells were assessed. $\mathrm{OPP}_{2.5}$ had more complex constituents than $\mathrm{PPP}_{2.5}$, including large quantities of water-soluble ions, multiple metals and polycyclic aromatic hydrocarbons, as well as copies of bacterial and fungal genomes and endotoxins $(0.433 \mathrm{EU} / \mathrm{mg})$. In contrast, $\mathrm{PPP}_{2.5}$ contained low levels of water-soluble ions and metals, practically undetectable polycyclic aromatic hydrocarbons, no bacterial or fungal genomes and endotoxin contents were $<1 / 10$ of those of $\mathrm{OPP}_{2.5}(0.0419 \mathrm{EU} / \mathrm{mg})$. The main constituents of the water-soluble fractions of $\mathrm{PM}_{2.5}$ were ions, while relatively more polycyclic aromatic hydrocarbons were measured in fat-soluble fractions of $\mathrm{PM}_{2.5}$. $\mathrm{OPP}_{2.5}$ and $\mathrm{PPP}_{2.5}$ were more cytotoxic than the water-soluble and fat-soluble fractions of $\mathrm{PM}_{2.5}$. Therefore, the present study elected 
to further evaluate the toxic effects induced by these two insoluble solid particles in vivo.

The present study investigated the effects of $\mathrm{OPP}_{2.5}$ and $\mathrm{PPP}_{2.5}$ in male $\mathrm{BALB} / \mathrm{c}$ mice treated with instilled aerosols of $\mathrm{OPP}_{2.5}$ or PPP 2.5 . Pro-inflammatory cytokines and chemokines and other biochemical factors were measured in serum. The lungs, the major target organs, were analyzed histopathologically. Flow cytometry was utilized to analyze immune status by counting immune cells in the lungs and the levels of inflammatory cytokines and other biochemical factors in bronchoalveolar lavage fluid (BALF) were measured. The findings provided a foundation for future research into the mechanisms of toxicity induced by inhaled $\mathrm{PM}_{2.5}$.

\section{Materials and methods}

Animals. Specific pathogen-free male BALB/c mice $(n=36$; 6-8 weeks old; weight, 23-29 g pre-treatment and 20-27 g post-treatment) were obtained from the Laboratory Animal Center of the Academy of Military and Medical Science. The mice were housed at $20 \pm 1^{\circ} \mathrm{C}$, with $60 \%$ humidity and $12 / 12 \mathrm{~h}$ light/dark cycles, 4 mice per cage, according to the Guideline for Animal Experiments of the Academy of Military and Medical Sciences. All animals had free access to water and food and were allowed to acclimatize for 1 week prior to the experimental procedures. All animal experiments were approved by the Animal Ethics Committee of the Academy of Military and Medical Sciences (approval no. AMMS-13-2 015-013). No animals died unexpectedly prior to the end of this experiment. At the end of the experiment, the mice were euthanized via intraperitoneal injection of sodium pentobarbital $(\sim 150 \mathrm{mg} / \mathrm{kg})$. Death was determined by cessation of heartbeat or respiratory arrest.

PM sources and processing. $\mathrm{PM}_{2.5}$ sampling and $\mathrm{OPP}_{2.5}$ and $\mathrm{PPP}_{2.5}$ processing were described previously (17). Briefly, $\mathrm{PM}$ was collected during May and June with a $\mathrm{PM}_{10} / \mathrm{PM}_{2.5}$ high-volume air sampler (Thermo Fisher Scientific, Inc.) equipped with a $\mathrm{PM}_{2.5}$ pre-separator. Collection was performed in a typical urban area in Beijing, $18 \mathrm{~m}$ above ground level. $\mathrm{PM}_{2.5}$ was collected in a quartz filter (Pall Corporation) that was previously calcinated in a muffle furnace at $600^{\circ} \mathrm{C}$ for $2 \mathrm{~h}$ to remove organic substances. $\mathrm{OPP}_{2.5}$ was prepared by resuspending with double-distilled water post-sampled filters and mixed before use. $\mathrm{PPP}_{2.5}$ was obtained by removing water- and fat-soluble components using high-temperature and high-pressure sterilization, including baking at $180^{\circ} \mathrm{C}$ for $3 \mathrm{~h}$ to destroy microorganisms and remove endotoxins.

To prepare particle suspensions for the animal experiments, fractioned $\mathrm{OPP}_{2.5}$ and $\mathrm{PPP}_{2.5}$ particles were immediately suspended in sterile saline $(0.9 \% \mathrm{NaCl})$ prior to use and sonicated for $10 \mathrm{~min}$ in ice water mixture to obtain a uniform dispersion and prevent particle aggregation.

Experimental design and execution. $\mathrm{OPP}_{2.5}$ and $\mathrm{PPP}_{2.5}$ were suspended and sonicated in sterile saline to final concentrations of $1.6 \mathrm{mg} / \mathrm{ml}$. Mice were randomly divided into 3 groups ( $n=12 /$ group) and treated with $50 \mu 1$ sterile saline (control), $\mathrm{OPP}_{2.5}$ suspension or $\mathrm{PPP}_{2.5}$ suspension. According to a previous study (28), the instillation dose in the present study was $\sim 4$ times the inhaled dose of mice compared with the current atmospheric dose at $1 \mathrm{mg} / \mathrm{m}^{3}$ of $\mathrm{PM}_{2.5}$. Mice were weighed before and after treatment. Blood, tissues and BALF were collected $24 \mathrm{~h}$ post-treatment. Whole blood was collected for the determination of hematocrit and preparation of serum.

Prior to the experiment, mice were anesthetized with pentobarbital sodium $(\sim 0.08 \mathrm{~g} / \mathrm{kg})$ by intraperitoneal injection. Once a deep stage of anesthesia was attained (calm and regular breathing), mice were intratracheally instilled using a MicroSprayer Aerosolizer system (IA-1C and FMJ-250 High-Pressure Syringe; Penn-Century, Inc.) with $50 \mu 1$ isotonic sterile saline solution containing $80 \mu \mathrm{g} \mathrm{OPP}_{2.5}$ or $\mathrm{PPP}_{2.5}$. Saline solution was used for the controls. Each mouse was placed in a supine position, the mouth was opened and the tongue gently moved aside using forceps to better cannulate the trachea. The particles were suspended in the appropriate solution immediately prior to instillation as aforementioned. Following instillation, the mice were immediately observed for at least $1 \mathrm{~h}$ before being returned to their cages under the aforementioned controlled environmental conditions.

Serum preparation and biochemical analyses. At $24 \mathrm{~h}$ post-treatment, $300 \mu \mathrm{l}$ blood was collected from one of the retro orbital sinus into a $1.5 \mathrm{ml}$ centrifuge tube. Some blood was used for the determination of hematocrit. After incubating the blood at room temperature for 1-2 h, tubes were centrifuged at $825 \mathrm{x} \mathrm{g}$ for $10 \mathrm{~min}$ at $4^{\circ} \mathrm{C}$. The serum supernatants were collected and divided into aliquots and stored at $-80^{\circ} \mathrm{C}$ for the subsequent biochemical analyses on the pro-inflammatory cytokines and chemokines, and other clinical indicators.

Clinical indicators, including the activities of alanine aminotransferase (ALT), aspartate transaminase (AST), lactate dehydrogenase (LDH) and alkaline phosphatase (ALP), and the levels of total protein, albumin (ALB), globulin and creatinine were measured in serum using an automatic biochemical analyzer (7080; Hitachi, Ltd.). The concentrations of pro-inflammatory cytokines/chemokines, including mouse eotaxin, interleukin (IL) $1 \alpha$, IL-1 $\beta$, IL-6, leukemia inhibitory factor (LIF), IL-17, monocyte chemoattractant protein (MCP) 1, macrophage inflammatory protein (MIP)1 $\alpha$, MIP-2, vascular endothelial growth factor (VEGF) and tumor necrosis factor (TNF) $\alpha$ were determined in serum using Milliplex MAP multiplex immunoassay kits (Mouse Cytokine/Chemokine Panel I; MCYTOMAG-70; MilliporeSigma), according to the manufacturer's protocol. In addition, the concentration of C-reactive protein (CRP) in serum was determined using the Mouse CRP ELISA kit (cat. no. EK0977; Boster Biological Technology), according to the manufacturer's protocol. Results were normalized to the levels of hematocrit in blood. All experiments were performed in octuplicate.

Histopathology. The left lung of each mouse was submerged in $10 \%$ formalin at room temperature (RT) for $48 \mathrm{~h}$ and processed for histology. Paraffin blocks were prepared from dehydrated tissues (treated with gradient ethanol), and $3-\mu \mathrm{m}$-thick sections were stained with hematoxylin and eosin at RT for $\sim 5 \mathrm{~min}$, followed by analysis using a light microscope at x40 magnification, and the levels of inflammatory response were evaluated by assessing the alveolar structure 
and alveolar wall thickness in mice. All experiments were performed in triplicate.

Flow cytometry. Lung single-cell suspensions were prepared at $24 \mathrm{~h}$ post-treatment as described previously (29). Briefly, mice were euthanized via intraperitoneal injection of pentobarbital sodium $(\sim 150 \mathrm{mg} / \mathrm{kg})$ following treatment with $100 \mu \mathrm{l}$ of $500 \mathrm{U} / \mathrm{ml}$ heparin (Beijing Solarbio Science \& Technology Co., Ltd.) subcutaneously. The thorax and abdomen were opened, the left atrium excised and the lungs were perfused through the right ventricle with $15 \mathrm{ml}$ of phosphate-buffered saline. The trachea was exposed and cannulated, and the lung was inflated with $1 \mathrm{ml}$ of digestion buffer, containing $1.5 \mathrm{mg} / \mathrm{ml}$ collagenase A (cat. no. 10103586001; Roche Diagnostics), $1.5 \mathrm{U} / \mathrm{ml}$ of dispase II protease (cat. no. D4693; Sigma-Aldrich; Merck KGaA), 0.4 mg/ml DNase I (cat. no. D8071; Sangon Biotech Co., Ltd.), 10\% FBS (Gibco; Thermo Fisher Scientific, Inc.) and $10 \mathrm{mM}$ HEPES in Hanks' balanced salt solution (cat. no. 14025-092; Gibco; Thermo Fisher Scientific, Inc.). After the trachea was sealed with 3.0 sutures and the heart and mediastinal tissues were removed, the lung inflated with digestion buffer was placed in $5 \mathrm{ml}$ of digestion buffer and incubated at $37^{\circ} \mathrm{C}$ for 60 min with shaking. Following digestion, $\sim 25 \mathrm{ml}$ phosphate-buffered saline, $0.5 \%$ bovine serum ALB and $20 \mathrm{mM}$ EDTA were added. The cell suspensions and lung tissue were filtered through a $70-\mu \mathrm{m}$ strainer. After centrifuging the cell suspensions at $350 \mathrm{~g}$ at $4^{\circ} \mathrm{C}$ for $5 \mathrm{~min}$, the pellet was treated with red blood cell lysis solution (Tianjin Haoyang Biological Manufacture Co., Ltd.) and washed with phosphate-buffered saline in $0.5 \%$ bovine serum albumin (Amresco, LLC), then suspended in phosphate-buffered saline with $2 \%$ FBS.

After counting the lung cells using a Countess II FL automated counter (Thermo Fisher Scientific, Inc.), $\sim 2 \times 10^{6}$ cells from each mouse were incubated in blocking solution, consisting of phosphate-buffered saline containing $0.25 \%$ FcBlock (cat. no. 553141; BD Biosciences), for $15 \mathrm{~min}$ at $4^{\circ} \mathrm{C}$ and then stained with antibodies (a list of antibodies, clones, fluorochromes and concentrations are presented in Table SI) for $30 \mathrm{~min}$ at $4^{\circ} \mathrm{C}$. Following staining, cells were washed and fixed with $1 \%$ paraformaldehyde in phosphate-buffered saline for $30 \mathrm{~min}$ at $4^{\circ} \mathrm{C}$, then washed and resuspended in phosphate-buffered saline with $0.5 \%$ bovine serum albumin. Flow cytometry was conducted with a BD FACSymphony A5 flow cytometer using BD FACSDiva software 8.0 (BD Biosciences), and the data were analyzed using FlowJo software (version 10; FlowJo LLC). The present study used a previously published protocol (30) to analyze the immune status in the lung. Live $\mathrm{CD} 45^{+}$cells were gated, and myeloid cells were gated based on CD11c vs. CD11b. Total myeloid cells were then plotted as MerTK vs. CD64, and the MerTK ${ }^{+}$ $\mathrm{CD} 4^{+}$macrophage gate was plotted as CD11c vs. MHC II to illustrate the alveolar macrophages and interstitial macrophage (IM)1, IM2 and IM3. A macrophage-deficient gate was plotted with CD11c and MHC II to illustrate dendritic cells, which were plotted as CD11c vs. CD11b to identify $\mathrm{Batf}^{+}$and $\mathrm{Irf4}^{+}$dendritic cells. A macrophage/dendritic cell-deficient gate was plotted as Ly6G vs. CD11b to identify neutrophils $\left(\mathrm{CD} 11 \mathrm{~b}^{+} \mathrm{Ly}_{6 \mathrm{G}}{ }^{+}\right)$and a macrophage/dendritic cell/neutrophil-deficient gate was plotted as side scatter vs.

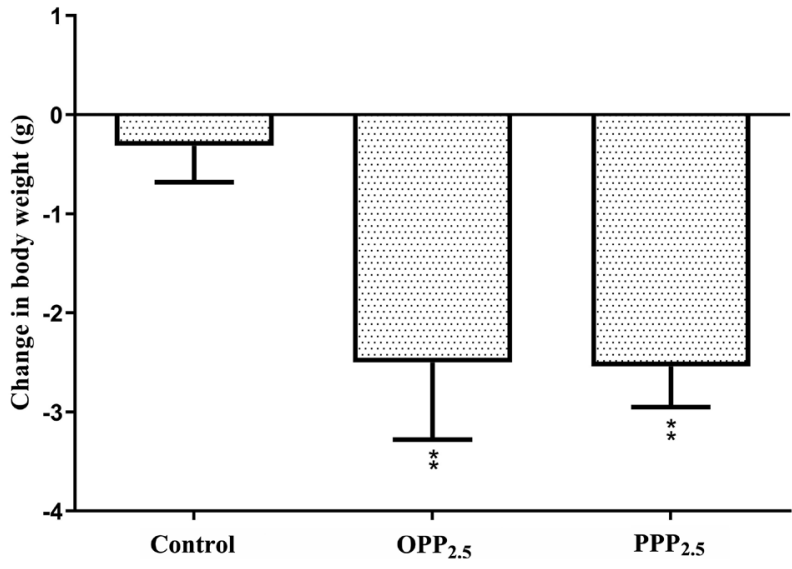

Figure 1. Changes in mouse body weight following intratracheal instillation with aerosolized $\mathrm{OPP}_{2.5}$ particles $(80 \mu \mathrm{g}), \mathrm{PPP}_{2.5}$ particles $(80 \mu \mathrm{g})$ or vehicle (50 $\mu 1$ sterile saline). Data are presented as the mean \pm standard error of the mean ( $\mathrm{n}=8$ /group). ${ }^{* *} \mathrm{P}<0.01$ vs. control. $\mathrm{OPP}_{2.5}$, original atmospheric particulate matter with a diameter $\leq 2.5 \mu \mathrm{m}$; $\mathrm{PPP}_{2.5}$, pure atmospheric particulate matter with a diameter $\leq 2.5 \mu \mathrm{m}$.

F4/80 to identify eosinophils and monocytes. All experiments were performed in quadruplicate.

BALF collection and biochemical analyses. Following sacrifice $24 \mathrm{~h}$ post-treatment, the tracheas were exposed and cannulated. The lungs were lavaged twice, each time by instilling a $0.7 \mathrm{ml}$ aliquot of isotonic saline solution and the two washes were pooled as BALF. The total lavage fluid from each mouse lung was combined and centrifuged at $400 \mathrm{xg}$ for $10 \mathrm{~min}$ at $4^{\circ} \mathrm{C}$ (3-18K; Sigma-Aldrich; Merck KGaA) and the supernatants were divided into aliquots and stored for subsequent determination. Levels of clinical indicators and pro-inflammatory cytokines/chemokines were measured in BALF as aforementioned for serum analyses. All experiments were performed in octuplicate.

Statistical analysis. SAS software (version 9.3; SAS Institute, Inc.) was used to analyze data. With the exception of the histopathological evaluation, all data are expressed as mean \pm standard error of the mean. Statistical differences were assessed by one-way ANOVA followed by Student-Newman-Keuls comparisons. Non-parametric Kruskal-Wallis test was performed followed by Dunn's test for data that did not conform to normality or homogeneity of variance. $\mathrm{P}<0.05$ was considered to indicate a statistically significant difference.

\section{Results}

Body weight. Mice were weighed before and after treatment with $\mathrm{OPP}_{2.5}$ and $\mathrm{PPP}_{2.5}$ (Fig. 1). Body weight decreased in the treated groups compared with controls. There was no significant difference between mice treated with $\mathrm{OPP}_{2.5}$ and $\mathrm{PPP}_{2.5}$.

Serum biochemical analyses. The activities or contents of AST, globulin, total protein and creatinine in serum did not differ significantly between the treatment and control groups (data not shown). Compared with levels in the control group, 
A

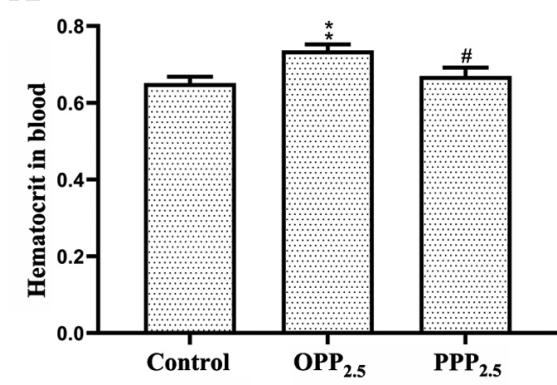

D

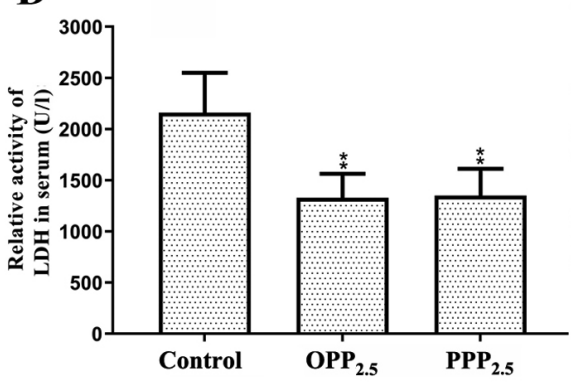

B

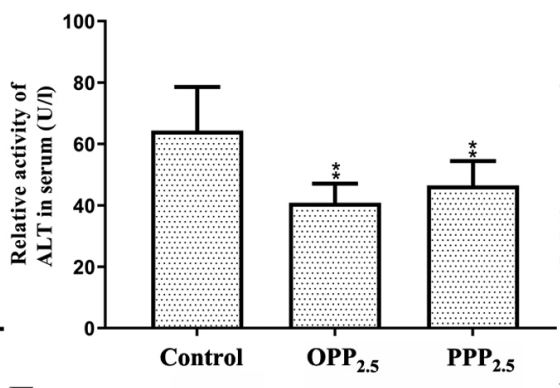

C



$\mathbf{F}$
$\mathbf{E}$

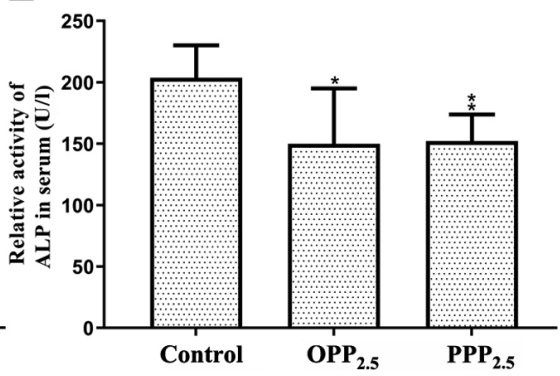



Figure 2. Levels of biochemical factors in blood and serum following exposure to $\mathrm{OPP}_{2.5}$ particles $(80 \mu \mathrm{g}), \mathrm{PPP}_{2.5}$ particles $(80 \mu \mathrm{g})$ or vehicle (50 $\mu$ l sterile saline). (A) Hematocrit level. Relative activities of (B) ALT, (C) ALB, (D) LDH and (E) ALP. (F) Relative content of MCP1. Results were normalized to hematocrit levels. Data are presented as mean \pm standard error of the mean ( $\mathrm{n}=8$ /group). ${ }^{*} \mathrm{P}<0.05$ and ${ }^{* * *} \mathrm{P}<0.01$ vs. control. ${ }^{*} \mathrm{P}<0.05$ vs. $\mathrm{OPP}_{2.5}$ group. $\mathrm{OPP}_{2.5}$, original atmospheric particulate matter with a diameter $\leq 2.5 \mu \mathrm{m} ; \mathrm{PPP}_{2.5}$, pure atmospheric particulate matter with a diameter $\leq 2.5 \mu \mathrm{m}$; ALT, alanine aminotransferase; ALB, albumin; LDH, lactate dehydrogenase; ALP, alkaline phosphatase; MCP1, monocyte chemoattractant protein.



Control

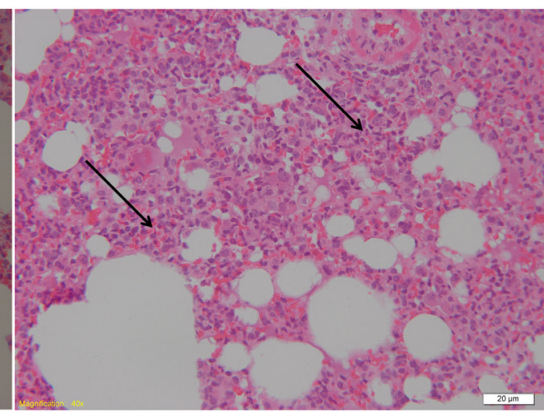

$\mathrm{OPP}_{2.5}$

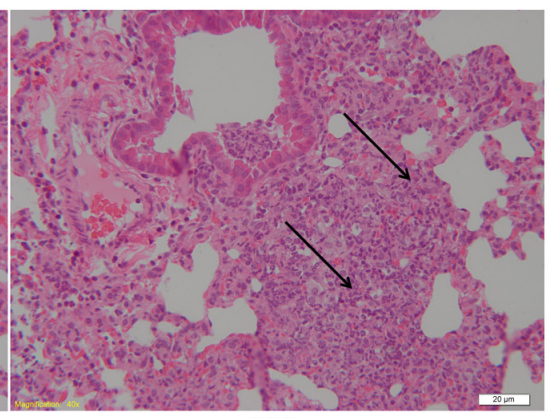

$\mathbf{P P P}_{2.5}$

Figure 3. Stained sections of lung tissues following exposure to $\mathrm{OPP}_{2.5}$ particles $(80 \mu \mathrm{g}), \mathrm{PPP}_{2.5}$ particles $(80 \mu \mathrm{g})$ or vehicle $(50 \mu 1$ sterile saline). Widening alveolar septa (black arrows) and notable inflammatory cell infiltration were induced by $\mathrm{OPP}_{2.5}$ and $\mathrm{PPP}_{2.5}$. Magnification, $\mathrm{x} 40$ (n=3/group). $\mathrm{OPP}_{2.5}$, original atmospheric particulate matter with a diameter $\leq 2.5 \mu \mathrm{m} ; \mathrm{PPP}_{2.5}$, pure atmospheric particulate matter with a diameter $\leq 2.5 \mu \mathrm{m}$.

the blood hematocrit in the $\mathrm{OPP}_{2.5}$ group was significantly higher compared with controls (Fig. 2A). Mice treated with $\mathrm{OPP}_{2.5}$ or $\mathrm{PPP}_{2.5}$ had lower serum ALT, LDH and ALP activities compared with controls (Fig. 2B, D and E). Furthermore, serum ALB levels decreased in the $\mathrm{OPP}_{2.5}$ group compared with controls (Fig. 2C). With the exception of ALB and hematocrit, clinical indicator levels did not differ significantly between the $\mathrm{OPP}_{2.5}$ and $\mathrm{PPP}_{2.5}$ groups.

Serum levels of eotaxin, IL-1 $\alpha$, IL-1 $\beta$, IL-6, LIF, IL-17, MIP-1 $\alpha$, MIP-2, VEGF, TNF- $\alpha$ and CRP did not differ significantly between groups (data not shown). Serum MCP-1 levels increased in the $\mathrm{OPP}_{2.5}$ group compared with the control and $\mathrm{PPP}_{2.5}$ groups (Fig. 2F).

Histopathology. Lung tissue structure in the control group was normal, with almost all alveolar walls intact. There were interstitial inflammatory changes in the lungs of mice treated with $\mathrm{OPP}_{2.5}$ or $\mathrm{PPP}_{2.5}$ (Fig. 3). These included a widening of the alveolar septa and inflammatory cell infiltration. Inflammatory responses did not differ between the $\mathrm{OPP}_{2.5}$ and $\mathrm{PPP}_{2.5}$ groups.

Immune status. The flow cytometry gating scheme of the present study is shown in Fig. 4A. The number of CD $45^{+}$cells in the lungs from the treated groups was higher compared with that from the control group (Fig. 4B). Among these, the numbers of interstitial macrophages (Fig. 4D) and neutrophils (Fig. 4E) increased significantly in the treated groups compared with in the control group. Additionally, the numbers of alveolar macrophages (Fig. 4C), dendritic cells (Fig. 4F) and monocytes (Fig. 4I) increased significantly in the $\mathrm{OPP}_{2.5}$ group but not in the $\mathrm{PPP}_{2.5}$ group compared with in the control group. The most accumulated dendritic cells in the $\mathrm{OPP}_{2.5}$ group were Irf4 $^{+}$cells (Fig. 4H), not Batf3 ${ }^{+}$cells (Fig. 4G). The numbers 
A

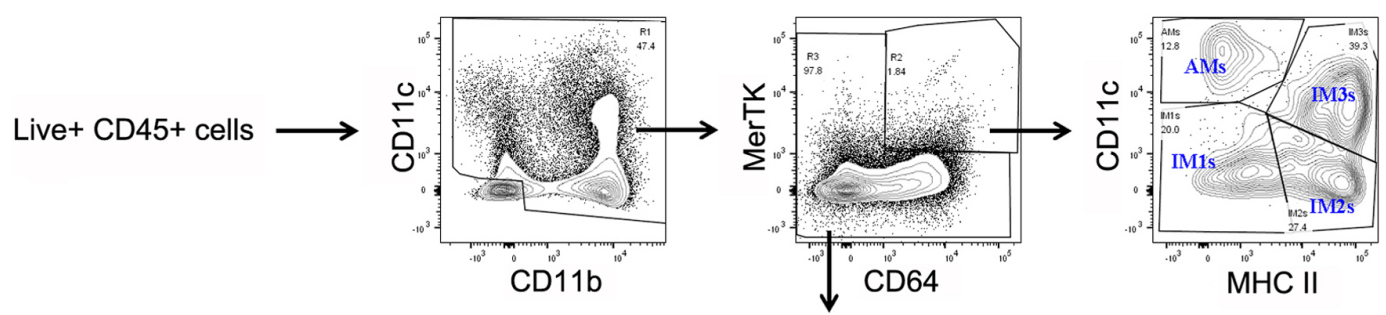

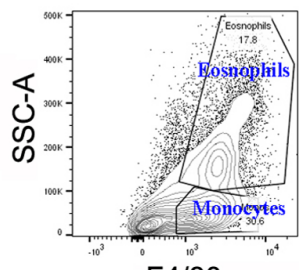

F4/80

B
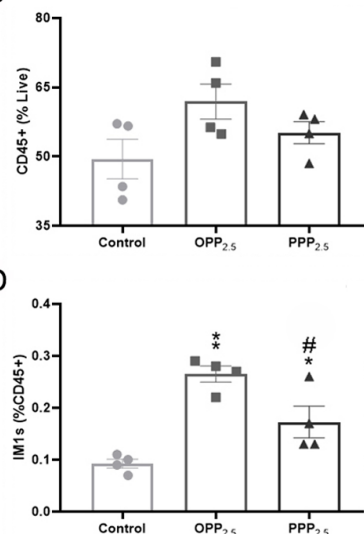

F

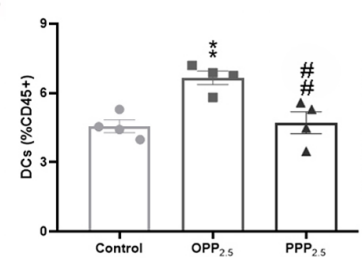

$\mathrm{H}$

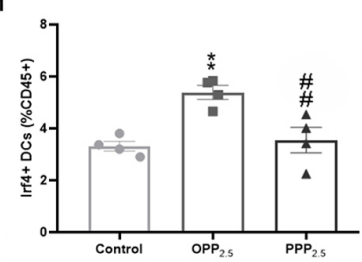

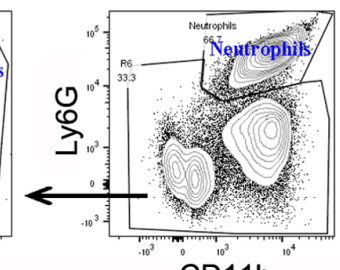

CD11b

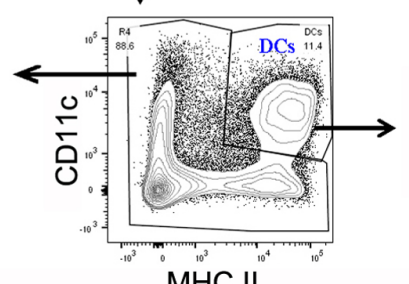

C
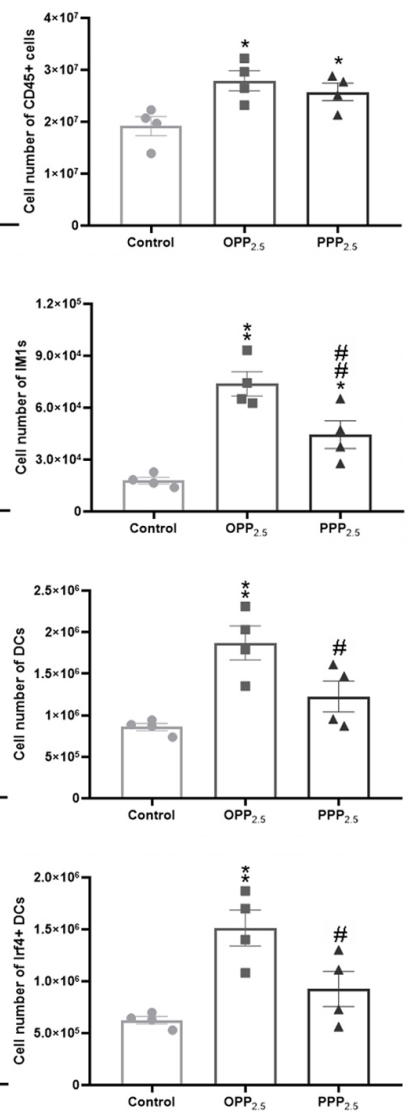

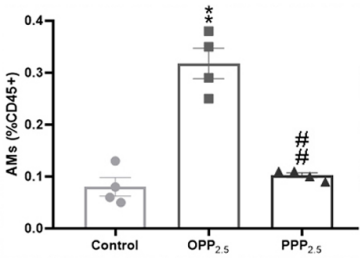

E
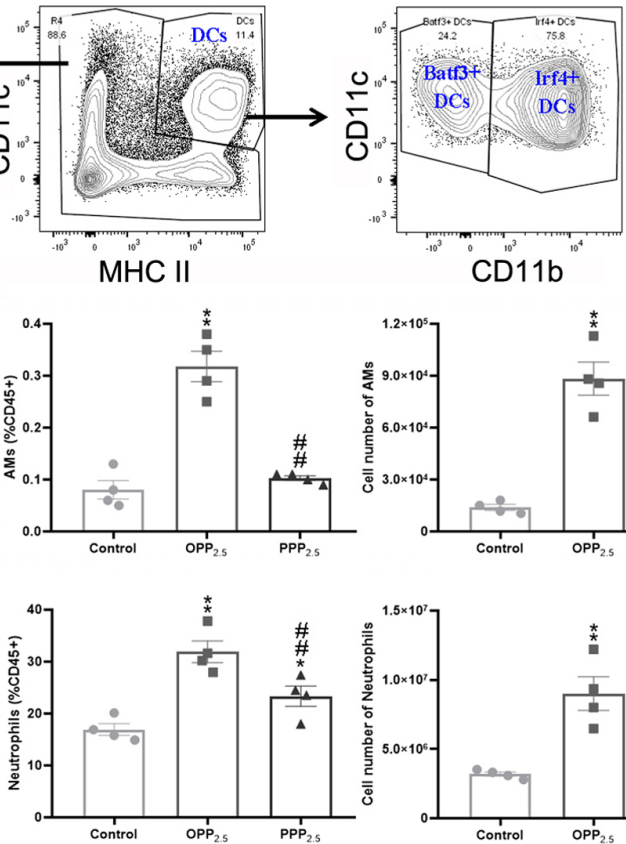

CD11b
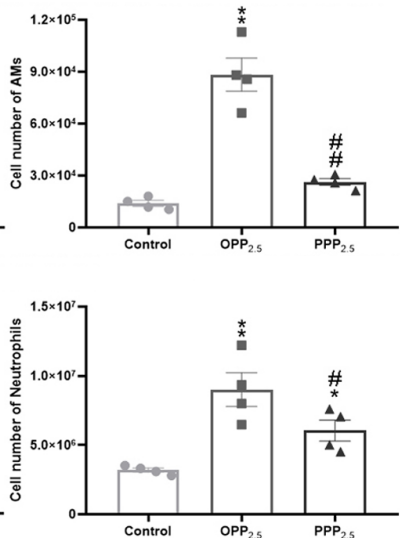

G
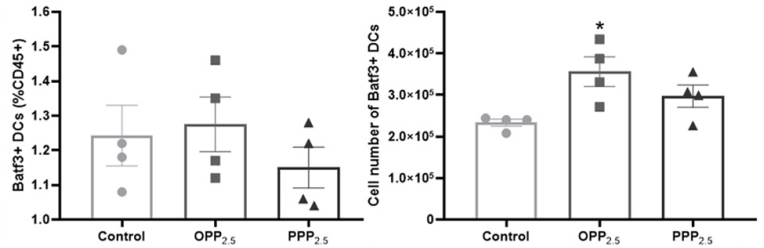

I
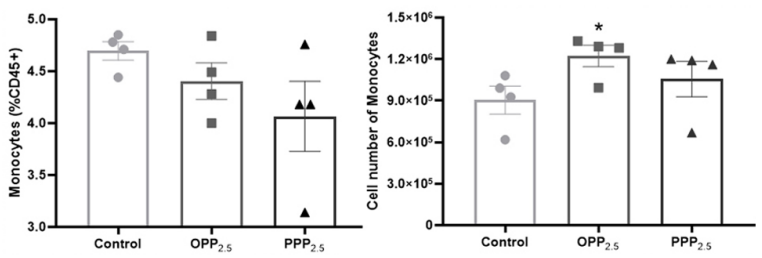

Figure 4. Comparison of pulmonary immune cell numbers obtained by flow cytometry following exposure to OPP 2.5 particles $(80 \mu \mathrm{g}), \mathrm{PPP}_{2.5}$ particles $(80 \mu \mathrm{g})$ or vehicle (50 $\mu \mathrm{l}$ sterile saline). (A) Fluorescence-activated cell sorting gating strategy used to identify pulmonary major immune cells. Live CD45 ${ }^{+}$cells were gated and myeloid cells were gated on CD11c vs. CD11b. Total myeloid cells were then plotted as MerTK vs. CD64 and the MerTK ${ }^{+} \mathrm{CD}_{4}{ }^{+}$macrophage gate was plotted as CD11c vs. MHC II to illustrate the AMs and IM1, IM2 and IM3. A macrophage-deficient gate was plotted with CD11c and MHC II to illustrate DCs, which were plotted as CD11c vs. CD11b to identify Batf3 ${ }^{+}$and Irf4 ${ }^{+}$DCs. A macrophage/DC-deficient gate was plotted as Ly6G vs. CD11b to identify

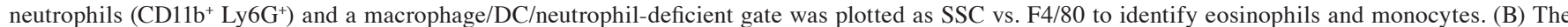
proportion of $\mathrm{CD}^{2} 5^{+}$cells in living cells and the absolute number of $\mathrm{CD}^{+} 5^{+}$cells in each sample from treated and control groups. The proportion of (C) AMs, (D) IM1s, (E) neutrophils, (F) DCs, (G) Batf3 $3^{+}$, (H) Irf4 ${ }^{+}$and (I) monocytes in CD45 cells and their absolute number. The circles represent the corresponding data of each mouse in the control group, the squares represent the corresponding data of each mouse in the $\mathrm{OPP}_{2.5}$ group, and the triangles represent the corresponding data of each mouse in the $\mathrm{PPP}_{2.5}$ group. Data are presented as mean \pm standard error of the mean ( $\mathrm{n}=4 /$ group). ${ }^{*} \mathrm{P}<0.05$ and ${ }^{* *} \mathrm{P}<0.01 \mathrm{vs}$. control. ${ }^{\#} \mathrm{P}<0.05$ and ${ }^{\# \#} \mathrm{P}<0.01$ vs. $\mathrm{OPP}_{2.5}$ group. $\mathrm{OPP}_{2.5}$, original atmospheric particulate matter with a diameter $\leq 2.5 \mu \mathrm{m} ; \mathrm{PPP}_{2.5}$, pure atmospheric particulate matter with a diameter $\leq 2.5 \mu \mathrm{m} ; \mathrm{CD}$, cluster of differentiation; MHC, major histocompatibility complex; AMs, alveolar macrophages; IM, interstitial macrophage; DC, dendritic cell; SSC, side scatter.

of IM2 and 3 cells and eosinophils did not differ between the treated and control groups (Fig. S1).

BALF biochemical analyses. BALF levels of ALT, ALB, creatinine, globulin, total protein and ALP did not differ significantly between the treated and control groups (data not shown). The activity of AST (Fig. 5A) and LDH (Fig. 5B) were significantly higher in BALF from the treated groups compared with controls; however, there was no significant difference between the $\mathrm{OPP}_{2.5}$ and $\mathrm{PPP}_{2.5}$ groups. These 
$\mathbf{A}$

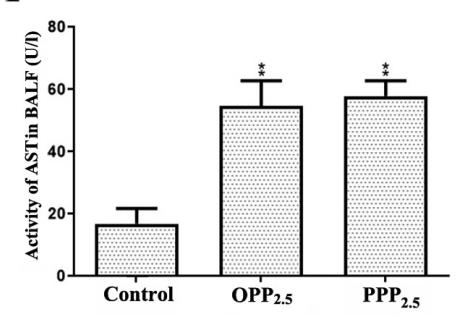

D

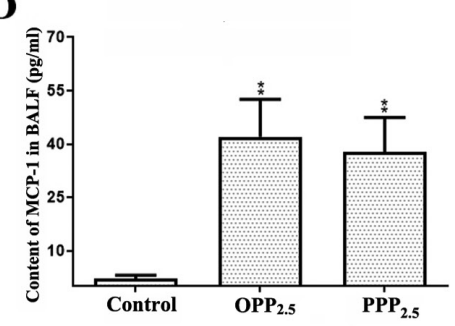

G

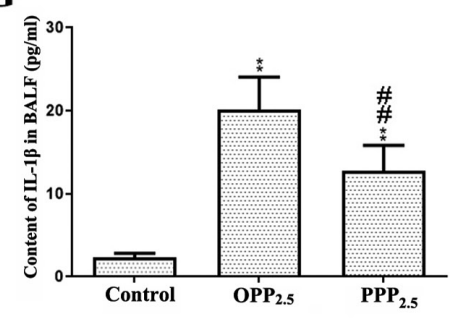

$\mathbf{J}$

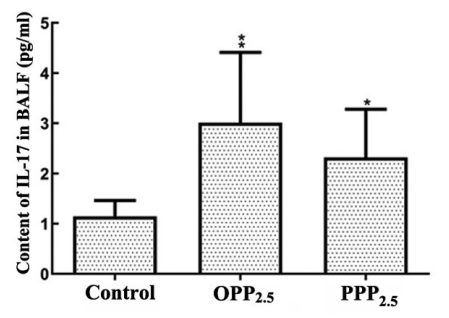

M

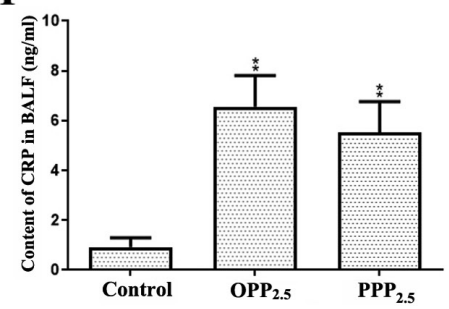

B

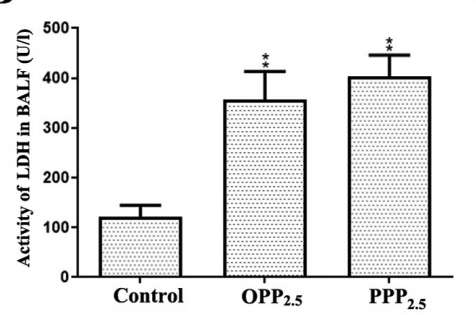

$\mathbf{E}$

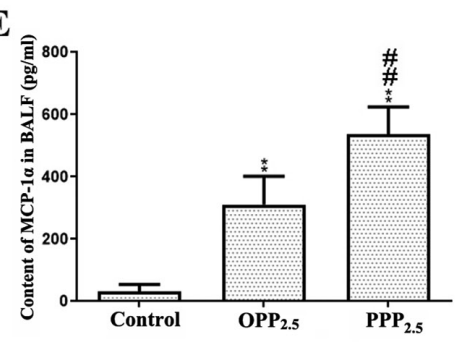

$\mathbf{H}$

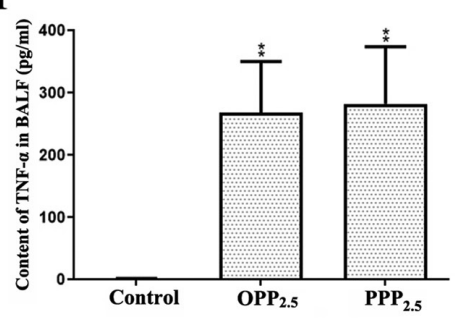

K



C

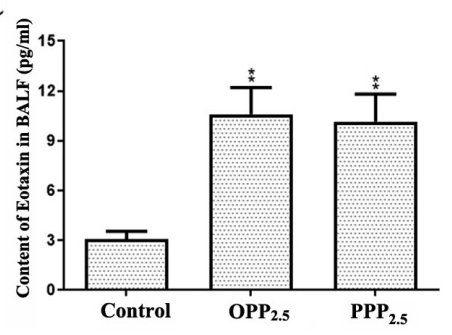

F

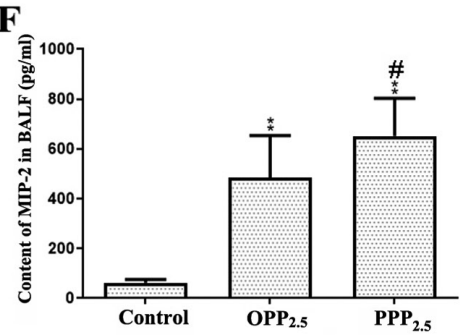

I

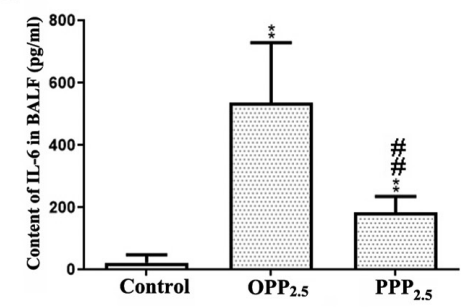

L

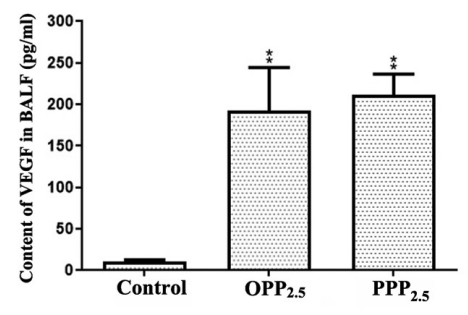

Figure 5. Levels of biochemical factors (A) AST, (B) LDH, (C) eotaxin, (D) MCP-1, (E) MIP-1 $\alpha$, (F) MIP-2, (G) IL-1 $\beta$, (H) TNF- $\alpha$, (I) IL-6, (J) IL-17, (K) LIF, (L) VEGF and (M) CRP in BALF from mice treated with $\mathrm{OPP}_{2.5}$ particles $(80 \mu \mathrm{g}), \mathrm{PPP}_{2.5}$ particles $(80 \mu \mathrm{g})$ or vehicle $(50 \mu 1 \mathrm{sterile}$ saline). Data are presented as mean \pm standard error of mean ( $\mathrm{n}=8$ /group). ${ }^{*} \mathrm{P}<0.05$ and ${ }^{* *} \mathrm{P}<0.01$ vs. control. ${ }^{*} \mathrm{P}<0.05$ and ${ }^{\# \#} \mathrm{P}<0.01$ vs. OPP 2.5 group. AST, aspartate transaminase; $\mathrm{LDH}$, lactate dehydrogenase; MCP, monocyte chemoattractant protein; MIP, macrophage inflammatory protein; IL, interleukin, TNF, tumor necrosis factor; LIF, leukemia inhibitory factor; VEGF, vascular endothelial growth factor; CRP, C-reactive protein; BALF, bronchoalveolar lavage fluid; OPP 2.5 , original atmospheric particulate matter with a diameter $\leq 2.5 \mu \mathrm{m}$; $\mathrm{PPP}_{2.5}$, pure atmospheric particulate matter with a diameter $\leq 2.5 \mu \mathrm{m}$.

results indicated that acute inhalation of $\mathrm{OPP}_{2.5}$ or $\mathrm{PPP}_{2.5}$ damages alveolar-capillary barriers and cell membranes in the lung.

IL-1 $\alpha$ levels in BALF did not differ between groups (data not shown). Levels of eotaxin, MCP-1, MIP-1 $\alpha$, MIP-2, IL-1 $\beta$, TNF- $\alpha$, IL-6, IL-17, LIF, VEGF and CRP were significantly higher in the treated groups compared with controls (Fig. 5C-M). Levels of MIP-1 $\alpha$ and MIP-2 were higher in the $\mathrm{PPP}_{2.5}$ group compared with the OPP ${ }_{2.5}$ group. Levels of IL-1 $\beta$ and IL-6 were higher in the $\mathrm{OPP}_{2.5}$ group compared with the $\mathrm{PPP}_{2.5}$ group.

\section{Discussion}

$\mathrm{OPP}_{2.5}$ has more complex constituents than $\mathrm{PPP}_{2.5}$ (27). The composition of $\mathrm{PPP}_{2.5}$ is simple for relatively pure solid particles, having almost no complex constituents adsorbed into particle surfaces. The aim of the present study was 
to determine whether pure solid $\mathrm{PM}_{2.5}$ exerts toxic effects similar to those of original $\mathrm{PM}_{2.5}$ with its complex constituents. The results demonstrated that mouse body weight decreased to varying degrees following acute exposure, perhaps due to the influence of anesthesia. However, treatment still decreased body weight. Hematocrit levels in mice treated with $\mathrm{OPP}_{2.5}$ were slightly elevated, suggesting minor dehydration. Decreased activity of ALT, LDH and ALP in mice treated with $\mathrm{OPP}_{2.5}$ and $\mathrm{PPP}_{2.5}$ and decreased ALB in mice treated with $\mathrm{OPP}_{2.5}$ indicated that the treatment may have induced mild malnutrition, which may explain the observed weight loss.

Serum levels of cytokine MCP-1 were higher in the $\mathrm{OPP}_{2.5}$ group compared with the control and $\mathrm{PPP}_{2.5}$ groups. MCP-1 promotes monocyte adhesion to vascular endothelial cells, which enables mononuclear cells to mediate immune phagocytosis and scavenging (31). The results indicated that $\mathrm{OPP}_{2.5}$ and $\mathrm{PPP}_{2.5}$ cause acute toxic effects at the whole-body level, such as weight loss and mild malnutrition. Furthermore, $\mathrm{OPP}_{2.5}$ causes minor dehydration and systemic inflammation.

To assess lung toxicity, lung damage was evaluated using histopathology, localized counts of major immune cells and cytokines, and clinical parameters. Lung histopathology reported inflammatory changes in the treated groups, with inflammatory cell infiltration into the alveolar interstitial space. This was confirmed by flow cytometry, which recorded numerous immune cells (cluster of differentiation $45^{+}$cells) in the lungs of treated mice, particularly IM1 and neutrophils in both treated groups and alveolar macrophages, dendritic cells and monocytes in the $\mathrm{OPP}_{2.5}$ group. Neutrophils have been proposed to mediate acute lung injury (32) and IM1 form the branch of interstitial macrophages that influence pulmonary fibrotic processes (33); however, its function in PM-treated mice requires further study. Alveolar macrophages usually inhabit the position of interface between pulmonary mucosa and the external environment, sense immunostimulation directly and maintain immune tolerance (33). Dendritic cells are important regulators in the innate and adaptive immune responses (34). The results demonstrated that PM, particularly $\mathrm{OPP}_{2.5}$, stimulate the innate immune response in mice, leading to the accumulation of numerous immune cells in the lung 24 h post-treatment.

Treatment with PM increased AST and LDH in BALF in the present study. AST was primarily derived from plasma exudation and reflects damage to the alveolar-capillary barrier. $\mathrm{LDH}$, an enzyme located in the cytoplasm, is released when cell membranes are damaged or disintegrate following cell death (35). The results indicated that, to a certain degree, cell membranes and parenchymal cells in the lung were damaged by $\mathrm{OPP}_{2.5}$ and $\mathrm{PPP}_{2.5}$.

The levels of multiple pro-inflammatory cytokines/chemokines increased in BALF following treatment in the present study. Eotaxin is a chemoattractant that recruits eosinophils (36) and MIP-1 $\alpha$ attracts lymphocytes, monocytes and neutrophils to an inflammatory infection site and mediate immune cell infiltration, positioning and activation in tissues (37). MIP-2 specifically recruits neutrophils, macrophages and lymphocytes to sites of inflammation following particle exposure (38) and enhances neutrophil participation in immune responses (16). This explains the observed inflammatory cell infiltration via histopathology and flow cytometry, which demonstrated the accumulation of macrophages and neutrophils in both treated groups and monocytes in the $\mathrm{OPP}_{2.5}$ group. Numerous eosinophils in the lung were not reported and the higher levels of MIP-1 $\alpha$ and MIP-2 in the PPP 2.5 group did not correspond to the expected accumulation of macrophages, neutrophils and monocytes. This may be due to eotaxin measured in BALF not being effectively released into the bloodstream in the $\mathrm{PPP}_{2.5}$ group or that other cytokines are involved in the chemotaxis of macrophages, neutrophils and monocytes to the lung.

IL-6 is an important mediator of fever and of acute-phase responses. It is also an anti-inflammatory factor that inhibits pulmonary inflammation and fibrosis (39). TNF- $\alpha$ is involved in apoptosis, cell differentiation and cell recruitment (40). As early biochemical mediators of pulmonary inflammation (41), TNF- $\alpha$ and IL-1 are involved in the initial stage of inflammation (42) and are released by resident macrophages to promote adhesion of circulating inflammatory cells to the endothelium (42). These two cytokines also induce the release of chemoattractant factors, including IL-6, MIP-2 and MCP-1, all of which attract inflammatory cells into the alveoli $(16,41,43)$ and enhance inflammatory and immune responses. IL-1 $\alpha$, IL-1 $\beta$ and TNF- $\alpha$ increase mRNA expression of LIF (44), an anti-inflammatory factor that is upregulated during peripheral inflammation (45). VEGF can bind to the VEGF receptor on the surface of vessel endothelial cells, enhancing vascular permeability and promoting the formation of blood vessels $(46,47)$. Upregulation of VEGF is often interpreted as a protective attempt to restore tissue homeostasis $(48,49)$. Analyses of pro-inflammatory cytokines in BALF indicated extensive inflammation in the lungs of mice treated with $\mathrm{OPP}_{2.5}$ or $\mathrm{PPP}_{2.5}$ $24 \mathrm{~h}$ post-treatment, with higher levels of IL-1 $\beta$ and IL- 6 in the $\mathrm{OPP}_{2.5}$ group. These findings were consistent with the flow cytometry analysis, which recorded numerous immune cells, including neutrophils and macrophages, in the lungs of treated mice, particularly in the $\mathrm{OPP}_{2.5}$ group. However, due to precise regulatory networks, increased levels of cytokines promoting inflammatory and immune responses triggered a concomitant increase in the levels of LIF, which can limit excessive responses (50).

Overall, the results of the current study for $\mathrm{OPP}_{2.5}$ were consistent with those of previous reports, suggesting that intratracheal instillation of PM in rodents induced pulmonary and systemic inflammation (16,51-54). Previous studies have demonstrated that water-soluble components and metals such as manganese, chromium, titanium, iron, copper, zinc, nickel and molybdenum in particulate matter may be associated with the generation of reactive oxygen species $(55,56)$. Oxidative stress is considered to be positively associated with induction of inflammation (57). In the present study, $\mathrm{PPP}_{2.5}$, which is comprised of pure solid particles without complex constituents adsorbed into the surface, caused pulmonary inflammation in mice. However, the systemic and pulmonary inflammatory responses were weaker than those induced by $\mathrm{OPP}_{2.5}$. The reason may be that less water-soluble components and metals were absorbed onto the surface of $\mathrm{PPP}_{2.5}$, as demonstrated by a previous study (27). These results provide a new perspective on the acute toxicity of PM and a reference for evaluating other 
pollutants. The acute toxicity of pure solid particles should be considered in tandem with that of the constituents that adsorb onto the particle surface.

Additionally, the toxicities and constituents of particles may be associated with wind direction, region or/and season $(58,59)$. These factors were not considered in the present study; however, they have little effect on the conclusion. However, one limitation of the present study was that the normal daily inhaled dose of the mice at the beginning of the study was not considered and should be investigated by future studies. Another limitation was that the local expression level of cytokines in the lungs was not assessed, and histological score was not performed, which could be investigated in future studies. Furthermore, the small number of mice in each group for flow cytometry may also be a limitation, which can be improved in future studies, and the toxicity of chronic exposure to pure solid particles should be assessed in the future.

\section{Acknowledgements}

Not applicable.

\section{Funding}

The present study was supported by the National Science Foundation of China (grant no. 41205102).

\section{Availability of data and materials}

All data generated and/or analyzed during the present study are included in this published article.

\section{Authors' contributions}

ZJ, ZW, LH and JL designed the present study. ZJ, LH and WY performed the experiments. ZJ analyzed data and wrote the manuscript draft. JL and ZW revised the final manuscript. ZW and LH confirm the authenticity of all the raw data. All authors read and approved the final manuscript.

\section{Ethics approval and consent to participate}

All animal experiments in the present study were approved by the Animal Ethics Committee of the Academy of Military and Medical Sciences (approval no. AMMS-13-2015-013).

\section{Patient consent for publication}

Not applicable.

\section{Competing interests}

The authors declare that they have no competing interests.

\section{References}

1. Nemmar A, Hoet PHM, Vanquickenborne B, Dinsdale D, Thomeer M, Hoylaerts MF, Vanbilloen H, Mortelmans L and Nemery B: Passage of inhaled particles into the blood circulation in humans. Circulation 105: 411-414, 2002.
2. Yoon S, Han S, Jeon KJ and Kwon S: Effects of collected road dusts on cell viability, inflammatory response, and oxidative stress in cultured human corneal epithelial cells. Toxicol Lett 284: 152-160, 2018

3. Jerrett M: Atmospheric science: The death toll from air-pollution sources. Nature 525: 330-331, 2015.

4. Oberdorster G: Pulmonary effects of inhaled ultrafine particles. Int Arch Occup Environ Health 74: 1-8, 2001.

5. Donaldson K, Stone V, Seaton A and MacNee W: Ambient particle inhalation and the cardiovascular system: Potential mechanisms. Environ Health Perspect 109 (Suppl 4): S523-S527, 2001.

6. Lim SS, Vos T, Flaxman AD, Danaei G, Shibuya K, Adair-Rohani H, Amann M, Anderson HR, Andrews KG, Aryee $\mathrm{M}$, et al: A comparative risk assessment of burden of disease and injury attributable to 67 risk factors and risk factor clusters in 21 regions, 1990-2010: A systematic analysis for the global burden of disease study 2010. Lancet 380: 2224-2260, 2012.

7. Pope CA III, Burnett RT, Thun MJ, Calle EE, Krewski D, Ito K and Thurston GD: Lung cancer, cardiopulmonary mortality, and long-term exposure to fine particulate air pollution. JAMA 287: 1132-1141, 2002.

8. Hart JE, Spiegelman D, Beelen R, Hoek G, Brunekreef B, Schouten LJ and van den Brandt P: Long-term ambient residential traffic-related exposures and measurement error-adjusted risk of incident lung cancer in the netherlands cohort study on diet and cancer. Environ Health Perspect 123: 860-866, 2015.

9. Chen C, Zhu P, Lan L, Zhou L, Liu R, Sun Q, Ban J, Wang W, Xu D and Li T: Short-term exposures to PM2.5 and cause-specific mortality of cardiovascular health in China. Environ Res 161: 188-194, 2018.

10. Ulrich MM, Alink GM, Kumarathasan P, Vincent R, Boere AJ and Cassee FR: Health effects and time course of particulate matter on the cardiopulmonary system in rats with lung inflammation. J Toxicol Environ Health A 65: 1571-1595, 2002.

11. Muller B, Seifart C and Barth PJ: Effect of air pollutants on the pulmonary surfactant system. Eur J Clin Invest 28: 762-777, 1998.

12. Burch WM: Passage of inhaled particles into the blood circulation in humans. Circulation 106: e141-142; author reply e141-142, 2002.

13. Du Y, Xu X, Chu M, Guo Y and Wang J: Air particulate matter and cardiovascular disease: The epidemiological, biomedical and clinical evidence. J Thorac Dis 8: E8-E19, 2016.

14. Lee BJ, Kim B and Lee K: Air pollution exposure and cardiovascular disease. Toxicol Res 30: 71-75, 2014.

15. Obot CJ, Morandi MT, Beebe TP, Hamilton RF and Holian A: Surface components of airborne particulate matter induce macrophage apoptosis through scavenger receptors. Toxicol Appl Pharmacol 184: 98-106, 2002.

16. Mantecca P, Farina F, Moschini E, Gallinotti D, Gualtieri M, Rohr A, Sancini G, Palestini P and Camatini M: Comparative acute lung inflammation induced by atmospheric PM and size-fractionated tire particles. Toxicol Lett 198: 244-254, 2010.

17. Jiao ZG, Fu XL, Wen ZB, Li JS, Li N, Zhang K, Wang J and Hu LF: Toxicological study at imflammatory factors and DNA damages effects of Beijing atmospheric $\mathrm{PM}_{2.5}$ and its different fractions to pulmonary epithelial cells A549 of human. China Environ Sci : 1579-1588, 2016 (In Chinese).

18. Hiura TS, Kaszubowski MP, Li N and Nel AE: Chemicals in diesel exhaust particles generate reactive oxygen radicals and induce apoptosis in macrophages. J Immunol 163: 5582-5591, 1999.

19. Ghio AJ, Stonehuerner J, Dailey LA and Carter JD: Metals associated with both the water-soluble and insoluble fractions of an ambient air pollution particle catalyze an oxidative stress. Inhal Toxicol 11: 37-49, 1999

20. Prahalad AK, Soukup JM, Inmon J, Willis R, Ghio AJ, Becker S and Gallagher JE: Ambient air particles: Effects on cellular oxidant radical generation in relation to particulate elemental chemistry. Toxicol Appl Pharmacol 158: 81-91, 1999.

21. Rumelhard M, Ramgolam K, Auger F, Dazy AC, Blanchet S, Marano F and Baeza-Squiban A: Effects of PM2.5 components in the release of amphiregulin by human airway epithelial cells. Toxicol Lett 168: 155-164, 2007.

22. Xu H, Wang X, Pöschl U, Feng S, Wu D, Yang L, Li S, Song W, Sheng $\mathrm{G}$ and $\mathrm{Fu}$ J: Genotoxicity of total and fractionated extractable organic matter in fine air particulate matter from urban Guangzhou: Comparison between haze and nonhaze episodes. Environ Toxicol Chem 27: 206-212, 2008. 
23. Liu FY, Ding MY, Wang FF and Li J: Cytotoxicity of different compositions of coal-fired $\mathrm{PM}_{2.5}$ on vascular endothelial cells. Res Environ Sci 24: 684-690, 2011 (In Chinese).

24. Cao Q, Qian XL, Zhang S and Song WM: Cytotoxicity of soluble and insoluble components of atmospheric fine particles. Acta Scientiae Circumstantiae 28: 1167-1172, 2008 (In Chinese)

25. Pozzi R, De Berardis B, Paoletti L and Guastadisegni C: Inflammatory mediators induced by coarse (PM2.5-10) and fine (PM2.5) urban air particles in RAW 264.7 cells. Toxicology 183: 243-254, 2003.

26. Qian XL, Song WM and Cao Q: Oxidative injury of alveolar epithelium cell 11 rs induced by coaine carbon black. J Toxicol 22: $14-16,2008$.

27. Jiao ZG, Li JY, Wen ZB, Li J, Gao J, Li N and Wang H: Chemical and biological components analysis of $\mathrm{PM}_{2.5}$ and its different fractions in summer atmosphere in Beijing urban areas. Chin J Environ Engineering: 5009-5015, 2016 (In Chinese)

28. He M, Ichinose T, Yoshida S, et al: PM2. 5. 5re in Beijing urban areas. Chinese journal of $\mathrm{f}$ inflammatory response in macrophages and type II alveolar cells. J Appl Toxicol 37: 1203-1218, 2017

29. Yu YR, O'Koren EG, Hotten DF, Kan MJ, Kopin D, Nelson ER, Que L and Gunn MD: A protocol for the comprehensive flow cytometric analysis of immune cells in normal and inflamed murine non-lymphoid tissues. PLoS One 11: e0150606, 2016.

30. Gibbings SL, Thomas SM, Atif SM, McCubbrey AL, Desch AN Danhorn T, Leach SM, Bratton DL, Henson PM, Janssen WJ and Jakubzick CV: Three unique interstitial macrophages in the murine lung at steady state. Am J Respir Cell Mol Biol 57: 66-76, 2017.

31. Gerszten RE, Garcia-Zepeda EA, Lim YC, Yoshida M, Ding HA, Gimbrone MA Jr, Luster AD, Luscinskas FW and Rosenzweig A: MCP-1 and IL-8 trigger firm adhesion of monocytes to vascular endothelium under flow conditions. Nature 398: 718-723, 1999.

32. Sapoznikov A, Gal Y, Falach R, Sagi I, Ehrlich S, Lerer E, Makovitzki A, Aloshin A, Kronman C and Sabo T: Early disruption of the alveolar-capillary barrier in a ricin-induced ARDS mouse model: Neutrophil-dependent and -independent impairment of junction proteins. Am J Physiol Lung Cell Mol Physiol 316: L255-L268, 2019.

33. Byrne AJ, Maher TM and Lloyd CM: Pulmonary macrophages: A new therapeutic pathway in fibrosing lung disease? Trends Mol Med 22: 303-316, 2016.

34. Greter M, Helft J, Chow A, Hashimoto D, Mortha A, Agudo-Cantero J, Bogunovic M, Gautier EL, Miller J, Leboeuf M, et al: GM-CSF controls nonlymphoid tissue dendritic cell homeostasis but is dispensable for the differentiation of inflammatory dendritic cells. Immunity 36: 1031-1046, 2012.

35. Drent M, Cobben NA, Henderson RF, Wouters EF and van Dieijen-Visser M: Usefulness of lactate dehydrogenase and its isoenzymes as indicators of lung damage or inflammation. Eur Respir J 9: 1736-1742, 1996.

36. Kim GH, Park YS, Jung KW, Kim M, Na HK, Ahn JY, Lee JH, Kim DH, Choi KD, Song HJ, et al: An increasing trend of eosinophilic esophagitis in korea and the clinical implication of the biomarkers to determine disease activity and treatment response in eosinophilic esophagitis. J Neurogastroenterol Motil 25: 525-533, 2019

37. Pi XM, Li ZZ, Ma YR and Li DW: MIP-1 $\alpha$ enhances trans-endothelial migration of CIK cells in lung cancer patients with brain metastasis. J China Med University 45: 141-144, 2016 (In Chinese)

38. Driscoll KE, Hassenbein DG, Carter JM, Kunkel SL, Quinlan TR and Mossman BT: TNF alpha and increased chemokine expression in rat lung after particle exposure. Toxicol Lett 82-83: $483-489,1995$

39. Xu DQ, Huang NH, Wang Q and Liu HG: Study of ambient $\mathrm{PM}_{2.5}$ on the influence of the inflammation injury and the immune function of subchronic exposure rats. Wei Sheng Yan Jiu 37: 423-428, 2008 (In Chinese).

40. Akash MSH, Rehman K and Liaqat A: Tumor necrosis factor-alpha: Role in development of insulin resistance and pathogenesis of type 2 diabetes mellitus. J Cell Biochem 119: $105-110,2018$

41. Henderson RF: Use of bronchoalveolar lavage to detect respiratory tract toxicity of inhaled material. Exp Toxicol Pathol 57 (Suppl 1): S155-S159, 2005.

42. Finkelstein JN, Johnston C, Barrett T and Oberdorster G: Particulate-cell interactions and pulmonary cytokine expression. Environ Health Perspect 105 (Suppl 5): S1179-S1182, 1997.
43. Tessier PA, Naccache PH, Clark-Lewis I, Gladue RP, Neote KS and McColl SR: Chemokine networks in vivo: Involvement of $\mathrm{C}-\mathrm{X}-\mathrm{C}$ and $\mathrm{C}-\mathrm{C}$ chemokines in neutrophil extravasation in vivo in response to TNF-alpha. J Immunol 159: 3595-3602, 1997.

44. Wetzler M, Talpaz M, Lowe DG, Baiocchi G, Gutterman JU and Kurzrock R: Constitutive expression of leukemia inhibitory factor RNA by human bone marrow stromal cells and modulation by IL-1, TNF-alpha, and TGF-beta. Exp Hematol 19: 347-351, 1991.

45. Liu J, Yu H and $\mathrm{Hu} \mathrm{W}$ : LIF is a new p53 negative regulator. J Nat Sci 1: e131, 2015.

46. Wakabayashi Y, Iwaya M, Akita M, Takeuchi W, Yamazaki K and Iijima A: Pulmonary tumor thrombotic microangiopathy caused by urothelial carcinoma expressing vascular endothelial growth factor, platelet-derived growth factor, and osteopontin. Intern Med 55: 651-656, 2016.

47. Zhang RP and Guo PF: Study progress of vascular endothelial growth factor. Med Recapitulate 14: 2258-2260, 2008 (In Chinese).

48. Lahm T, Crisostomo PR, Markel TA, Wang M, Lillemoe KD and Meldrum DR: The critical role of vascular endothelial growth factor in pulmonary vascular remodeling after lung injury. Shock 28: 4-14, 2007.

49. Campbell AI, Zhao Y, Sandhu R and Stewart DJ: Cell-based gene transfer of vascular endothelial growth factor attenuates monocrotaline-induced pulmonary hypertension. Circulation 104: 2242-2248, 2001

50. West NR: Coordination of immune-stroma crosstalk by il- 6 family cytokines. Front Immunol 10: 1093, 2019.

51. Kodavanti UP, Schladweiler MC, Ledbetter AD, Hauser R, Christiani DC, McGee J, Richards JR and Costa DL: Temporal association between pulmonary and systemic effects of particulate matter in healthy and cardiovascular compromised rats. J Toxicol Environ Health A 65: 1545-1569, 2002.

52. Stoeger T, Reinhard C, Takenaka S, Schroeppel A, Karg E, Ritter B, Heyder J and Schulz H: Instillation of six different ultrafine carbon particles indicates a surface area threshold dose for acute lung inflammation in mice. Environ Health Perspect 114: 328-333, 2006.

53. Upadhyay S, Ganguly K, Stoeger T, Semmler-Bhenke M, Takenaka S, Kreyling WG, Pitz M, Reitmeir P, Peters A, Eickelberg O, et al: Cardiovascular and inflammatory effects of intratracheally instilled ambient dust from Augsburg, Germany, in spontaneously hypertensive rats (SHRs). Part Fibre Toxicol 7: 27, 2010.

54. Sun X, Wei H, Young DE, Bein KJ, Smiley-Jewell SM, Zhang Q, Fulgar CCB, Castañeda AR, Pham AK, Li W and Pinkerton KE: Differential pulmonary effects of wintertime California and China particulate matter in healthy young mice. Toxicol Lett 278: 1-8, 2017.

55. Shuster-Meiseles T, Shafer MM, Heo J, Pardo M, Antkiewicz DS, Schauer JJ, Rudich A and Rudich Y: ROS-generating/ARE-activating capacity of metals in roadway particulate matter deposited in urban environment. Environ Res 146: 252-262, 2016.

56. Spagnolo AM, Ottria G, Perdelli F and Cristina ML: Chemical characterisation of the coarse and fine particulate matter in the environment of an underground railway system: Cytotoxic effects and oxidative stress-a preliminary study. Int J Environ Res Public Health 12: 4031-4046, 2015.

57. Zeng L, Lin L, Peng Y, Yuan D, Zhang S, Gong Z and Xiao W: 1-Theanine attenuates liver aging by inhibiting advanced glycation end products in d-galactose-induced rats and reversing an imbalance of oxidative stress and inflammation. Exp Gerontol 131: 110823, 2019.

58. Kamal AS, Rohr AC, Mukherjee B, Morishita M, Keeler GJ, Harkema JR and Wagner JG: PM2. 5-induced changes in cardiac function of hypertensive rats depend on wind direction and specific sources in Steubenville, Ohio. Inhal Toxicol 23: 417-430, 2011.

59. Cho CC, Hsieh WY, Tsai CH, Chen CY, Chang HF and Lin CS: In vitro and in vivo experimental studies of PM2. 5 on disease progression. Int J Environ Res Public Health 15: 1380, 2018.

This work is licensed under a Creative Commons Attribution-NonCommercial-NoDerivatives 4.0 International (CC BY-NC-ND 4.0) License. 